\title{
Electron microscopy of peripheral nerve fibers
}

By

\section{Ryohei Honjin}

Department of Anatomy, Faculty of Medicine, University of Kanazawa, Kanazawa

Considerable information on the submicroscopic structure of nerve fibers has been obtained from polarization opitical analyses and $\mathrm{x}$-ray diffraction studies, but such methods do not allow direct visualization of details lying beyond the light microscope's resolution. Successful application of the electron microscope to this problem with its increase in resolving power has made possible an extension of our knowlege of the ultrastructure of nerve fibers. As in the cases of other tissues, the electron microscope studies of the nerve fibers have been examined by means of two methods, i. e., technique of maceration and that of cutting ultrathin sections. Some of the previous researchers, i. e., Hess and Lansing (1953), have considered that the technique of maceration would be perhaps best not applied to mammalian nerve fibers, because the isolated elements are difficult to trace back to their original position within the nerve fiber. It seems, however, that the fragmentation procedures of nerve fibers afford an incomparable advantage for detailed discussion about them, though the greatest care must be exercised against misconstruction. Accordingly it is advisable to study the same materials with these two different methods. In the present paper, we intend to account for the submicroscopic structure of peripheral nerve fibers, utilizing the electron microscope with the macerating materials as well as with the thin sections.

\section{Materials and methods}

The sciatic nerves of adult mice were used. The nerves were removed, and stretched on a small card taking care to preserve the normal length of nerves as far as possible. They were placed in the following three kinds of fixatives: (1) $1 \%$ osmic acid amended with phosphate buffer ( $\mathrm{pH}$ 7.4). Fixation carried out in the cold chamber 
at 3 to $5^{\circ} \mathrm{C}$. for 4 hours; (2) $10 \%$ formalin neutralized with magnesium carbonate containing mammalian Ringer's solution at room temperature for 24 hours; and (3) Müller's solution at room temperature for three days. After fixation and thorough washing in several changes of distilled water, the materials were dehydrated through a graded series of alcohols and embedded in $\mathrm{n}$-butyl methacrylate monomer, according to the procedure outlined by New man, Borysko, and Swerdlow (1949). After polymerization of the monomer, using $2 \%$ benzoyl peroxide as a catalyst, the hardened blocks were trimmed to about $0.5 \mathrm{~mm}$ on a side and attached to a microtome specimen holder advanced by thermal expansion, which is a modification of the electrically heated specimen holder by Eden, Pratt, and Kahler (1950). All sections were cut with the edge of a safety razor attached to a knife-holder. Sections of suitable thinness $(0.1 \mu$ or less) were selected, passed through amyl acetate and acetone, and mounted on collodion membrane, and were subsequently transferred to the surface of copper mesh grids.

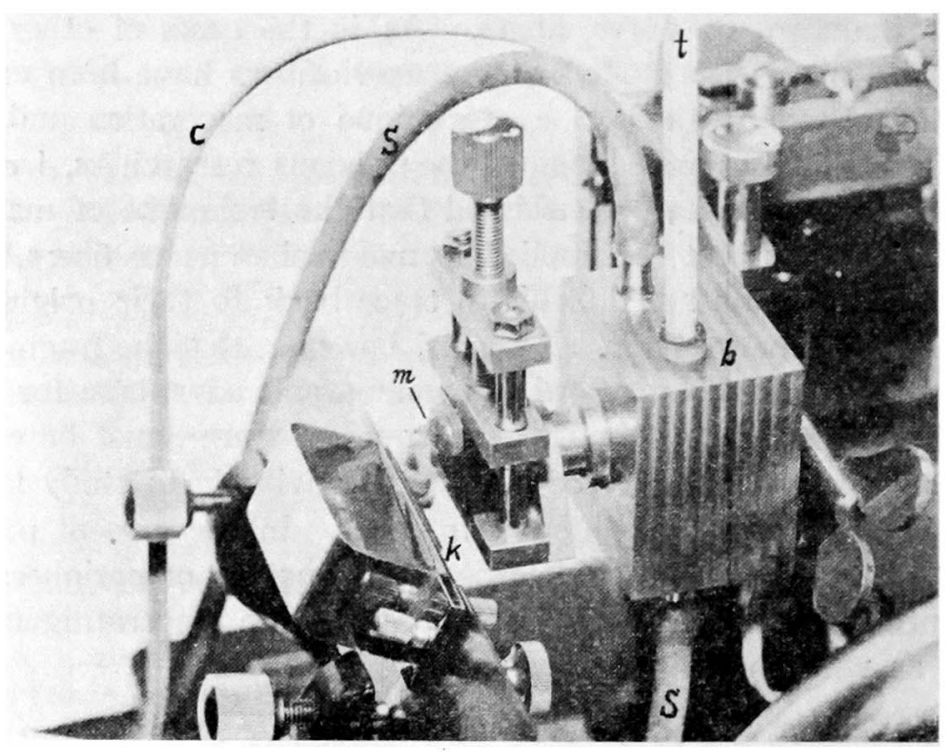

A modified specimen holder advanced by thermal expansion, which is electrically heated by nichrome wire and cooled by cold water. The holder is mounted in the Erma usual rotary microtome. The material embedded in methacrylate and attached to the holder $(\mathrm{m})$, the cutting knife and knife-holder $(\mathrm{k})$, and the heating and cooling box (b), which is provided with india-rubber stumps for the aqueduct (s), the electric cord for heater (c), and the thermsmeter $(t)$, are shown. 
Macerated preparations of nerve fibers were obtained as follows: After a rinsing in several changes of distilled water, the nerves fixed with osmic acid or formalin were fragmented with a pestle in a glass mortar, together with a small amount of distilled water, and the centrifuged suspensions were examined. The fragmented particles were mounted on collodion-coated electron microscope grids. Some of the grids were shadowed with chromium at an angle of $14^{\circ}$. HS-2 and HU-9 electron microscopes were used. Electron micrographs were taken at original magnifications of 2000 to $6000 \times$. Further photographic enlargement was employed as indicated. The most valuable fixative among those mentioned above osmic acid proved to be. Consequently our observations reported below are mainly based on the preparations treated with osmic acid, except where otherwise stated.

\section{Results}

\section{Myelinated fibers}

Axoplasm. In living giant axons of squid, birefringence studies of Bear, Schmitt, and Young (1937b) have shown a weak positive uniaxial birefringence indicating the presence of elongated particles in the axons. This longitudinal organization has been shown in the usual light microscopy by the so-called neurofibrils, which are usually noticed in the fixed axons, but sometimes observed in the living nerve fibers (De Rényi, 1929b; Weiss and Wang, 1936), and by several fibrous structures in the electron microscope studies of various types of vertebrate and invertebrate nerves (Richards, Steinbach, and Anderson, 1943; Takeda, 1947; De Robertis and Schmitt, 1948; Sasakawa and Hosomi, 1949; Schmitt and Geren, 1950; Schmitt, 1950; Fernández-Morán, 1950b; Roza, Morgan, Szent-Györgyi, and Wyckoff, 1950; Pease and Baker, 1951; Hess and Lansing, 1953).

Examination of thin sections of the well-fixed fibers shows that the space occupied by the axoplasm reveals the following three kinds of structures: a network of thin fibrils, long thread-like fibrils, and somewhat large elongated vesicles. The network of thin fibrils in the axons is seen both in thin sections fixed with osmic acid and those with formalin. As shown in figures 1,2 , and 3 , it consists of exceedingly thin, from 110 to $170 \AA$ wide fibrils, which anastomose freely with each other. They are occasionally stretched obliquely across the lumen of the axon, but are oriented mainly in the long axis of the fiber. A 
meshed net of axon fibrils is the result, which usually appears empty, but sometimes is masked by a few masses of adhering small granular material ( 50 to $200 \AA$ in diameter). The fibrils of this network are so small in diameter that it is difficult to determine whether they are tubular or not. This network of axon fibrils can also be seen in the fragmented preparations, in which it shows a much more beaded ap. pearance, being filled with a dense granular material (fig. 7), because the network in the fragmented preparations is not sectioned so thin as that in the section preparations. These thin fibrils of axon may correspond to the thin filaments which have been already noticed in the axons of many animals by Fernández-Morán (1950b), Schmitt and Geren (1950), and Hess and Lansing (1953). In our opinion, these fibrils are to be regarded as a product of the treatment involved in fixation and embedding which acts upon some linear organization of colloids and exaggerates the longitudinal organization of the axoplasm.

The long thread-like fibrils are scattered throughout the axoplasm and embedded in the network of axon fibrils (figs. 1, 2, 3, and 4). In longitudinal or oblique sections, they appear as fine, relatively long strings of vesicles ( 600 to $1000 \AA$ in diameter). Sometimes they anastomose with one another and form an elongated reticulum (fig. 3). In cross section, these elements appear as rings of variable diameter; they have borders more dense than their centers and thus give the impression that they are tubular (figs. 1 and 4). These long thread-like fibrils are readily distinguished from the axon fibrils by their tubular appearance and heavy thickness in diameter. They presumably correspond to the endoplasmic reticulum which is discovered in the glandular cells by Palade and Porter (1952) and later noticed in the axons of the guinea pigs by Hess and Lansing (1953). They may be interpreted as pro. bably the same as the basophilic element which has been noticed in squid axons by Bear, Schmitt, and Young (1937c).

In addition to the two elements mentioned above, elongated narrow vesicles are found in the axons. The width of the vesicles ranges from 0.2 to $0.35 \mu$, and rarely more (figs. 1,2 , and 4 ). They occur as long bodies. The length apparently is indefinite, since it is fortuitous if the thin section passes through their entire length. In cross sections, they appear as dots scattered widely in the axons (fig. 4). They may correspond to elongated mitochondria in the axons, as suggested by Pease and Baker (1951), Beams, van Breemen, Newfang, and Evans (1952), and Hess and Lansing (1953).

Some cytologists have-regarded the so-called neurofibrils as artifacts, 
because coarse fibrous structures can be precipitated by poor fixation and the appearance of neurofibrils is very often coupled with the shrinking effect of fixatives. Pease and Baker (1951) have examined rat nerves with the electron microscope and have concluded that the neurofibrils in the conventional sense are artifacts. On the contrary, Beams, van Breemen, Newfang, and Evans (1952) have reported that the neurofibrils are seen in electron micrographs, appearing in different sizes (150 to $3000 \AA$ ), and only the larger ones are seen under the light microscope. In our preparations, we could not find anything identifiable as neurofibrils which are usually seen in a light microscope. We believe the so-called neurofibrils to be artifacts caused by the fixing procedure. Richards, Steinbach, and Anderson (1943) have observed the contorted fibrillar structures composed of elongated particles aggregated linearly in extruded squid giant fiber axoplasm. Kenda (1947) has noticed the striated or beaded fibrils, about $200 \AA$ diameter, in the fragmented material of nerves. De Ropert is and Schmitt (1948) have studied the various types of vertebrate and invertebrate nerves, fragmented by sonic oscillations or by blending and observing characteristically dense-edged fibrils with a periodic cross banding, to which the descriptive term "neurotubules" is applied. Sasakawa and Hosomi (1949), based on the observations of the fragmented materials, have assumed that the axoplasm contains both the so.called neurotubules and the thin fibrils which are from 200 to $500 \AA$ in diameter and contain small granules in themselves. In the axons, however, we have seen nothing identifiable as neurotubules or striated fibrils reported by above mentioned authors, respectively. As shown in figure 7 , the collagen materials connected with the neurilemma and myelin particules appear to be very similar to the striated fibers and neurotubules of these authors. Consequently it is certain that the neurotubules and striated fibers are not axonic constituents, but a collagen character of the neurilemma sheath, as recognized afterwards in reexamination by Schmitt and Geren (1950).

Axolemma membrane. The axolemma has been a controversial subject for many years, hinging on the question as to whether it exists or not. Histologically, the existence of a membrane at the border between myelin sheath and axon has not been universally accepted. Some of the earlier histologists (Kaplan, 1902; De Rényi, 1929a) held that the axolemma is absent from living nerve fibers. They believed that there is protoplasmic connection between axon and myeline, while Schiefferdecker (1887) assumed that the axon is more dense at the 
periphery than in its interior. On the contrary, Mönckeberg and Bethe (1899) and Nageotte (1910) maintained the existence of a membrane, enveloping the axis cylinder. In the field of the electron microscope study, also two different observations about this subject have opposed each other. Rosa, Morgan, Szent-Györgyi, and Wyckoff (1950) have noticed the absence of an axolemma. On the contrary, Fernández-Morán (1950a, b), Pease and Baker (1951), Beams, van Breemen, Newfang, and Evans (1952), and Hess and Lansing (1953) have demonstrated a fine membrane covering the axon.

A thin membrane, which is located at the border between myelin sheath and axon, enveloping the latter, is found in the preparations of the present investigation. It would correspond to the postulated axolemma membrane. This membrane provides the basis for the thin network of axon fibrils and is closely adherent to the myeline sheath. We can find no space of Mauthner between axon and myelin sheath in well-fixed regions of the nerve fibers. However, occasionally the axon is mechanically pulled away from the myelin and the intimate sheath of the myelin is carried with the axon during sectioning. Under these circumstances, a fine membrane, axolemma membrane, as indicated in the figures 1 and 5, can be seen on the axon surface. The axolemma membrane is also confirmed in the thin sections fixed with Müller's solution, in which almost all the myelin substances are affected by treatment with alcohol, acetone or amyl acetate after fixation, and broken to irregular coarse masses, but the axolemma membrane can be clearly recognized (fig. 6). Consequently, the axolemma membrane appears to represent a constant structure in the myelinated fibers. We can find no densely woven thin fibrils which connect the myelin sheath with the fibrous structures of the axon, as suggested by Fernández. Morán (1950a).

Myelin sheath. The myelin sheath of the fresh fiber has been devoid of microscopic details in visible light. Nageotte (1911) has pointed out that after fixation with potassium bichromate and acetic acid, there is a marked tendency for the myelin sheath to separate in concentric lamellae or leaflets about the axon. He has reported the lamellar composition of the sheath in great detail and even assumed that each of the thicker lamellae consists of a certain number of unit lamellae. This conception of Nageotte has been supported by the polarized light studies of Schmidt (1935, 1936, 1937), Schmitt and Bear (1937, 1939), Bear and Schmitt (1937), Chinn and Schmitt (1937), and Bear, Schmitt, and Young (1937a), and by the x-ray diffraction studies of 
Handovsky (1933), Schmitt, Bear, and Clark (1935), Schmitt and Bear (1939), Bear, Palmer, and Schmitt (1941), Palmer and Schmitt (1941), and Schmitt, Bear, and Palmer (1941). According to these authors, the amount and sign of the birefringence reflects the relative amount of oriented lipid and protein in the myelin sheath, i. e., the sheath is described as being composed of concentrically wrapped layers of radially oriented bimolecular lipids, alternating with coaxial, possibly unimolecular, neurokeratinogenic protein lamellae running tangentially, and each unit layer of fresh mammalian myelin built up of these lipids and protein has a thickness in a radial direction of approximately $184 \AA$. Fernández-Morán (1950a, b) Hess and Lansing (1953) and others have seen these laminated thin layers in the electron micrographs.

In cross sections, the myelin sheath appears as a characteristic onion-peel-like laminated structure which is composed of alternating dark and light concentric layers (fig. 4). The dark layer is probably the lipid-containing band and the light one may be the protein band. The same type of lamination can be seen longitudinally oriented in the longitudinal sections, but it appears in wavy form which would be caused by the destruction at the time of dehydration and sectioning (fig. 1). Occasionally the myelin sheath fixed with osmic acid, especially that of the large-sized fiber, appears riddled with submicroscopic oval crevices (fig. 1). They may result from regularly occurring gaps between the individual lamellae. However, their distribution and appearance are very variable. They are sometimes absent; they connot be seen at all especial$\mathrm{ly}$ in the small-sized myelinated fibers. Conseqnently, it seems that they may be artifacts caused by the dehydration. The occurrence of them, however, suggests that the adhesion of each concentrically arranged lamella is less firm in the spots of these crevices, Generally speaking, the smaller myelinated fibers which would be well-fixed by osmic acid, show a more excellent laminated appearance than the larger ones. Our observations on the section preparations are not extensive enough to measure the thickness of individual dark and light laminated layers. Oblique interruptions of the myelin sheath, similar to Schmidt-Lanterman n incisures in the light microscope, are also observed in the longitudinal sections.

In fragmented preparations, the laminated organization of the myelin sheath and the individual lamellae can clearly be seen. In figure 8 , the upper third is occupied by the large mass of the myelin sheath from which thin ribbons of lamellae are seen to peel off to the center of the 
figure. These ribbons are composed of several unit lamellae which are found piled closely upon each other. The same kind of pile of myelin lamellae is also seen in figure 7 , in which 4 layers of lamellae can be easily distinguished in a single pile. It resembles a stratified piece of mica-plate. Some of the angular edges of the unit lamellae are seen to peel off and to turn up. Large pieces of unit lamellae can be isolated by the gentle, leisurely fragmentation of the osmic acid-fixed nerves (fig. 9). They are not preserved as well in formalin-fixed nerves in which it is often difficult to separate the myelin sheath into individual unit lamellae. The unit myelin lamella fixed with osmic acid resembles a transparent, flexible thin membrane and shows no distinct structure of its own. After shadow casting with chromium, it exhibits a characteristic fine granular appearance, to give an impression of the existence of granules, approximately from 100 to $300 \AA$ in diameter (fig. 10). The measurement of the thickness of the myelin lamellae was carried out on shadowed specimens, but its accuracy is limited by the resolving power of $30 \AA$ of our microscope. In figure 10 , there is seen a thin ribbon shadowed with chromium at an angle of $14^{\circ}$, which is composed of two layers of myelin lamellae piled upon each other. Two shadows of lamellae are seen at the margins of the lamellae. The shadow of the lower layer shows an average thickness of $70 \AA$ of this layer without the granular surface structure, which contributes from 30 to $90 \AA$ to give a total thickness of the lamella varying between 100 and $160 \AA$. The shadow of the upper layer contributes from 140 to $170 \AA$ in the thickness of this layer. According to the $\mathrm{x}$-ray diffraction studies of Schmitt, Bear, and Palmer (1941), in dry mammalian spinal roots the long-spacing identity period is $159 \AA$, of which one may regard about $134 \AA$ as being accounted for by the bimolecular layers of lipid, leaving about $25 \AA$ to be filled by protein, and in the fresh nerves the presence of water accounts for an additional $26 \AA$ resulting from protein swel. ling and from insertion of water molecules between protein-lipid or lipidlipid polar groups. Our measurement is in accord with the expectation of these researchers. The lower layer represents the thickness of the dried unit lamellae arranged concentrically. The value of 140 to $170 \AA$ determined for the upper layer shows a periodic spacing in the lamellar structure, corresponding to a shortened period brought about by drying. Schmitt, Bear, and Palmer (1941) have illustrated diagrammatically the possibility of protein lamellae occurring between the double layer of lipids, resulting in a structure consisting of thin sheets of protein cover- 
ed on both sides with lipid double layers. In our preparations we could find no finely perforated lamellae and grating structures suggested by Fernández-Morán (1950b).

Neurilemma. The myelin sheath is covered with a thin membrane, i. e., neurilemma sheath. It is not conspicuous in the section preparations, especially in optimally fixed fibers, because it is less dense than the myelin sheath and is directly adherent to the myelin. However, when it is mechanically torn away from the myelin during sectioning or shrinkage by dehydration (fig. 1), or when the myelin sheath is destroyed by alcohol during the embedding process (fig. 6), the neurilemma appears as an obvious sheath, in average thickness of $400 \AA$. Schwann cell nuclei are seen interposed between the neurilemma and the myelin. We have not been able to define the cytoplasm of Schwann cell except in the immediate vicinity of its nuclei. It seems that the neurilemma is in continuous connection with the cytoplasm of Schwann cells, which contains vesicles of about 0.3 to $0.4 \mu$ in diameter and with a surrounding membrane and internal ridges. These vesicles may be mitochondria of Schwann cells.

In macerated preparations, the neurilemma is seen peeled off as a thin membrane which consists of densely packed uniform granules. Closely attached to this membrane, there are found fibrils which are probably arranged mainly in the long axis of the fiber. These fibrils represent a characteristic repeating period of 600 to $660 \AA$ (fig. 7). This corresponds to the periodicity of collagen as determined by many investigators. Consequently these fibrils are considered to be collagen fibrils. The collagen elements in the nerve fibers have been described by Fernández-Morán (1950b), Pease and Baker (1951) and Hess and Lansing (1953). The so called neurotubules reported by De Robertis and Schmitt (1948) correspond to the collagen fibrils on the neurilemma invested with the hazy substance, as mentioned above.

\section{Non-myelinated fibers}

The non-myelinated fibers appear in groups between the myelinated ones in the nerve bundles. The structure of the axoplasm of the nonmyelinated fibers is very similar to that of the myelinated ones. The network of axon fibrils, the endoplasmic reticulum and the elongated mitochondria are present and exhibit the same features as in the myelinated axons (fig. 4). They are, however, very small in number as compared with those in the myelinated axons, probably because of the 
small amount of axoplasm in the non-myelinated fibers. Several nonmyelinated axons can be seen enclosed in the cytoplasm of a single Schwann cell (fig. 4). That is to say, many neurons are commonly enveloped by a single $\mathrm{Sch}$ wan $\mathrm{n}$ cell. Individual non-myelinated axons are bounded by the cytoplasm of the Schwann cell and its outer limiting membrane.

\section{Summary}

1. Ultrathin sections and macerated preparations of the sciatic nerves of adult mice have been examined with the electron microscope. Sections were prepared with a modification of the thermal expansion sectioning technique. Several fixatives were employed, and, of these, osmic acid proved best in researching the submicroscopic structures in the nerve fibers.

2. Exceedingly thin axon fibrils about 110 to $170 \AA$ in diameter were observed in the axons. They were predominantly oriented in the long axis of the fiber and were apparently anastomosing with one another to form a network. Endoplasmic reticulum, from 600 to $1000 \AA$ in diameter, was also found scattered throughout the axoplasm. They appear as tubular fibrils. Elongated narrow mitochondria, 0.2 to $0.35 \mu$ in width, were also found in the axoplasm. Neurofibrils in the conventional sense are to be regarded as artifact caused by fixation.

3. A thin membrane, axolemma membrane in the conventional sense, was observed at the border between myelinated lamellae and axoplasm.

4. The myelin sheath was composed of a characteristic laminated structure which was observed as alternating concentric dark and light lamellae in thin section preparations. This structure was identical with the flexible lamellar structure, isolated single or in piles, in the fragmented preparations. The periodicity in the lamellar structure was measured by means of shadow casts as being of 140 to $170 \AA$, corresponding to a shortened period brought about by drying. Schmidt-Lantermann incisures were also observed.

5. The myelin sheath was covered with neurilemma sheath consisting of a granular membrane, in average thickness of $400 \AA$. Mainly longitudinally arranged collagen fibrils were attached to this membrane. Schwann cell cytoplasm seems to continue to the neurilemma membrane.

6. Truly non-myelinated axons have been seen in the peripheral 
nerves. The contents of their axoplasm were similar to those of the myelinated fibers. Several non-myelinated axons were enclosed in the cytoplasm of a single Schwann cell and its outer limiting membrane.

\section{Acknowledgments}

The author wishes to thank Mr. K. Noda, Mr. T. Kanbe, and Mr. T. Nishimura for the photographs and Mr. Y. Uchiki for technical assistance in the specimen holder construction.

\section{References}

Beams, H.W., V.L. van Breemen, D. M. Newfang, and T.C. Evans 1952 A correlated study on spinal ganglion cells and associated nerve fibers with the light and electron microscopes. J. Comp. Neur., 93: 249-281.

Bear, R.S. and F.O. Schmitt 1937 Optical properties of the axon sheaths of crustacean nerves. J. Cell. and Comp. Physiol., 9: 275-287.

Bear, R.S, F. O. Schmitt, and J.Z. Young 1937a The sheath components of the giant nerve fibers of the squid. Proc. Roy. Soc. B, 123: 490-504. 1937b The ultrastructure of nerve axoplasm. Proc. Roy. Soc. B, 123: 505-519. 1937c Investigations on the protein constituents of nerve axoplasm. Proc. Roy. Soc. B, 123: 520-529.

Bear, R.S., K.J. Palmer, and F.O. Schmitt 1941 X-ray diffraction studies of nerve lipides. J. Cell. and Comp. Physiol., 17: 355-367.

Chinn, P. and F. O. Schmitt 1937 On the birefringence of nerve sheaths as studies in cross sections. J. Cell. and Comp. Physiol.. 9: 289-296.

De Rényi, G. St. 1929a The structure of cells in tissues as revealed by microdissection. III. Observations on the sheaths of myelinated nerve fibers of the frog. J. Comp. Neur., 48: 293-310.

_ 1929b The structure of cells in tissues as revealed by microdissection. IV. Observations on neurofibrils in the living nervous tissue. J. Comp. Neur., 48: 441-457.

De Robertis, E. and F.O. Schmitt 1948 An electron microscope analysis of certain nerve axon constituents. J. Cell. and Comp. Physiol., 31 : 1-23,

Eden, M., A.W. Pratt, and H. Kahler 1950 A microtome specimen holder advanced by thermal expansion. Rev. Sci. Instr., 21: 802-804.

Fernández-Morán, H. 1950a Electron microscope observations on the structure of the myelinated nerve fiber sheath. Exp. Cell. Res., 1: 143-149.

1950b Sheath and axon structures in the internode portion of vertebrate myelinated nerve fibers. An electron microscope study of rat and frog sciatic nerves. Exp. Cell. Res, 1: 309-340.

Handovsky, H. 1933 Röntgenographische Untersuchungen an erregter und geiähmter Nervensubstanz. Koll. Zeits., 62: 21-22.

Hess, A. and A.I. Lansing 1953 The fine structure of peripheral nerve fibers. Anat. Rec., 117: 175-200.

Ka pla n, L. 1902 Nervenfärbungen. (Neurokeratin, Markscheide, Axencylinder.) Ein Beitrag zur Kenntniss des Nervensystems. Arch. f. Psychiat., 35: 825-869. 
Mönckeberg, G. and A. Bethe 1899 Die Degeneration der markhaltigen Nervenfasern der Wirbelthiere unter hauptsächlicher Berücksichtigung des Verhaltens der Primitivfibrillen. Arch. mikr. Anat., 54 : 135-183.

Nageotte, J. 1910 Les étranglements de Ranvier et les espaces interannulaires des fibres nerveuses à myéline. C. R. de l'Asso. Anat., 12: 30-45.

1911 Betrachtungen über den tatsächlichen Bau und die künstlich hervorgerufenen Deformationen der markhaltigen Nervenfaser. Arch. mikr. Anat., 77: $245-279$.

Newman, S. B., E. Borysko, and M. Swerdlow 1949 New sectioning techniques for light and electron microscopy. Science, 110:66-68.

Palade, G. E. and K.R. Porter 1952 The endoplasmic reticulum of cells in situ (abstract). Anat. Rec., I12: 370.

Pease, D.C. and R.F. Baker 1951 Electron microscopy of nervous tissue. Anat. Rec., 110: $505-530$.

Richards, A.G., H.B. Steinbach, and T.F. Anderson 1943 Electron microscope studies of squid giant nerve axoplasm. J. Cell. and Comp. Physiol., 21 : 129-143.

Rozsa, G., C. Morgan, A. Szent-Györgyi, and R. W. G. Wyckoff 1950 The electron microscopy of sectioned nerve. Science, 112: 42-43.

Sasakawa, K. and T. Ho somi 1949 Contributions to the electron microscope committee of Japan, 53: B-3. (Japanese) (Cited from Sasakawa K. 1951 Electron microscopy. Tokyo, p. 311-316.)

Schiefferdecker, P. 1887 Beiträge zur Kenntniss des Baus der Nervenfasern. Arch. mikr. Anat., 30: 435-494.

Schmidt, W. J. 1935 Die Doppelbrechung der Markscheide osmierter Nervenfasern. Zeitsch. wiss. Mikr., 52: 158-165.

1936 Doppelbrechung und Feinbau der Markscheide der Nervenfasern. Zeitsch. Zellforsch., 23: 6`7-676.

1937 Über die Formdoppelbrechung der osmierten Markscheide.des Nerven. Zeitsch. wiss. Mikr., 54: 159-166.

Schmitt, F.O. 1950 The structure of the axon filaments of the giant nerve fibers of Loligo and Myxicola. J. Exp. Zool., 113: 499-515.

Schmitt, F. O. and R.S. Bear 1937 The opitical properties of vertebrate nerve axons as related to fiber size. J. Cell. and Comp. Physiol., 9: 261-273. 1939 The ultrastructure of the nerve axon sheath. Biol. Rev., 14: 27-50.

Schmitt, F. O., R.S. Bear, and G.L. Clark 1935 X-ray diffraction studies on nerve. Radiology, 25: 131-151.

Schmitt, F.O., R.S. Bear, and K. J. Palmer 1941 X-ray diffraction studies on the structure of the nerve myelin sheath. J. Cell. and Comp. Physiol, 18: 31-42.

Schmitt, F.O. and B.B. Geren 1950 The fibrous structure of the nerve axon in relation to the localization of "neurotubules." J. Exp. Med., 91: 499-504.

Takeda, Y. 1947 Electron microscopic studies on the ultrastructure of the cells. I. Electron microscopy of neurofibrils. Mankind and Heredity, 1: 87-97. (Japanese)

Weiss, P. and H. W ang 1936 Neurofibrils in living ganglion cells of the chick, cultivated in vitro. Anat. Rec., 67: 105-117. 


\section{Abbreviations}

Plates

a, axon.

af. axon fibrils.

ax, axolemma.

c, cytoplasm of the Schwann cell.

cf, collagen fibrils.

e, endoplasmic reticulum.

1, lamellae of the myelin sheath.

$\mathrm{Im}$, lamellar membrane of the myelin sheath.

$\mathrm{m}$, mitochondria.

$n$, nucleus of the Schwann cell.

nf, non-myelinated fibers.

$\mathrm{nl}$, neurilemma.

\section{Explanation of figures}

Plate 1

All illustrations are electron micrographs of thin sections of the sciatic nerves of mice. Scale indicates $1 \mu$.

1 Oblique section of large myelinated fibers. $\times 5,750$.

2 Enlargement of figure 1 showing the axon fibrils, endoplasmic reticulum, and elongated mitochondria. $\times 14,950$.

3 Longitudinal section of a large myelinated fiber. $\times 6,900$.

Plate 2

All illustrations are electron micrographs of thin sections of the sciatic nerves of mice. Scale indicates $1 \mu$.

4 Cross section of a group of large and small myelinated and non-myelinated fibers. $\times 6,900$.

5 Oblique section of myelinated fibers. Note a locus where the axolemma was pulled away from the mylin. $\times 10,500$.

6 Cross section of a myelinated fiber fixed with Müller's solution. Almost all the myelin sheaths are affected by lipid solvents after fixation and broken to irregular coarse masses. Axolemma and neurilemma can be observed. $\times 7,000$.

\section{Plate 3}

All illustrations are electron micrographs of macerated materials of the sciatic nerves of mice. Scale indicates $1 \mu$.

7 A network of axon fibrils, piles of myelin lamellae and collagen fibrils of neurilemma. The collagen fibrils connect the irregular clumps of the neurilemma and myelin with one another. $\times 12,000$.

8 Fragments of myelin lamellae. Note the thin lamellar ribbons which peel off from the large mass of the myelin sheath. $\times 8,000$.

9 Fragments of myelin lamellae. The single layer of unit lamellae is shown. $\times 8,000$.

10 Myelin lamellae shadowed with chromium. The shadowing cast at the margin of the lamellae and the fine granular surface structure can be seen. $\times 36,000$. 
Plate I

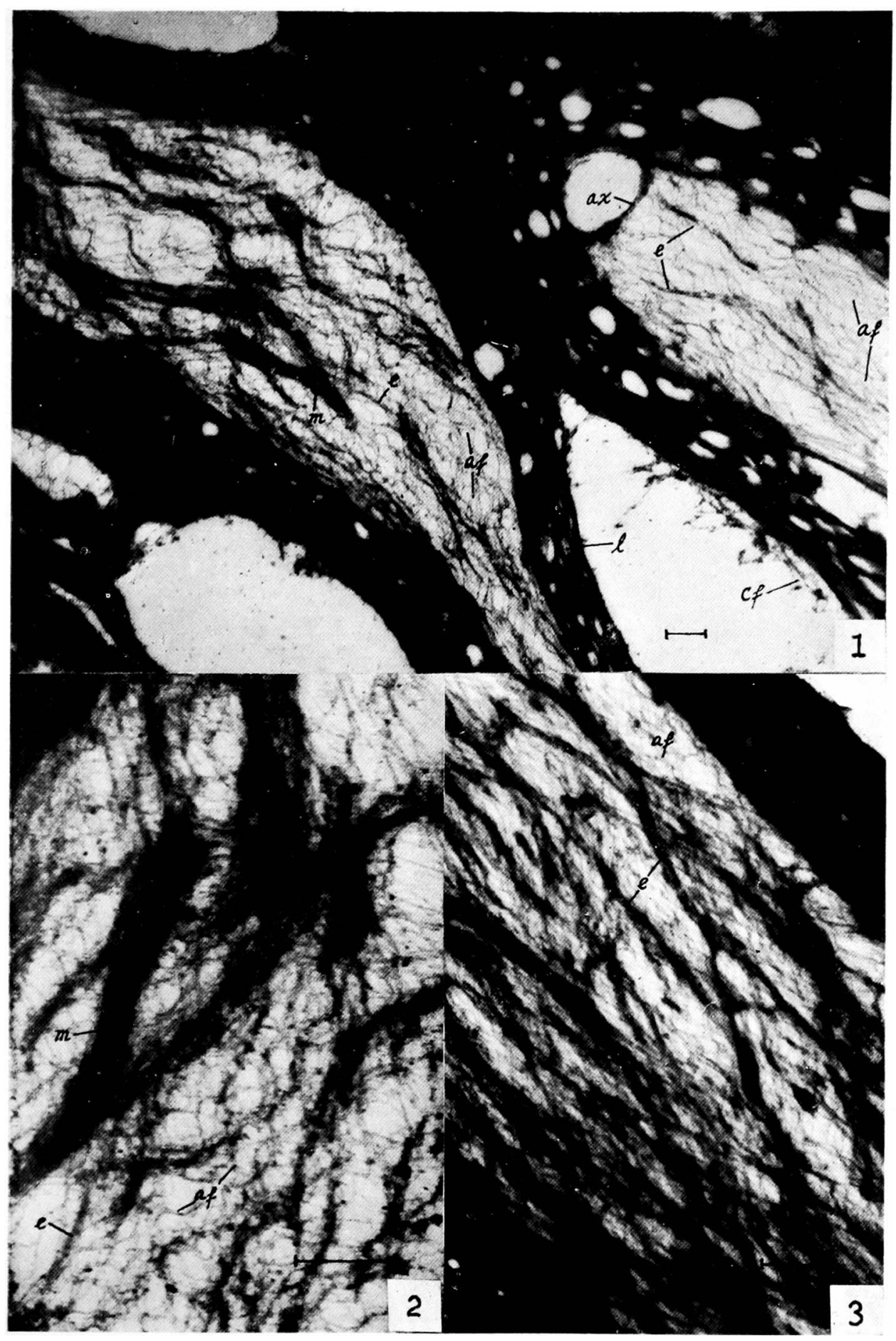

R. Honjin 
Plate II

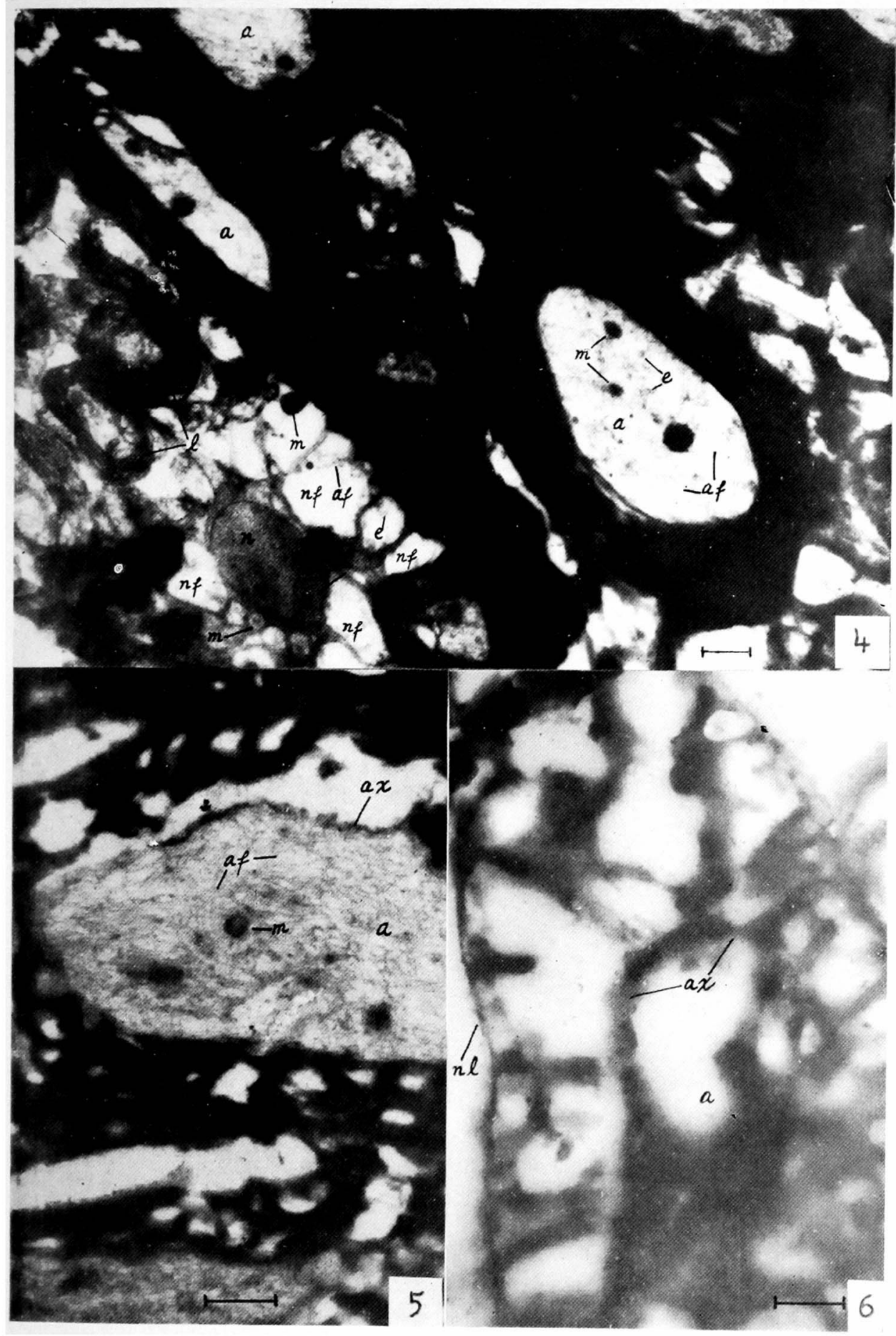

R. Honjin 
Plate III

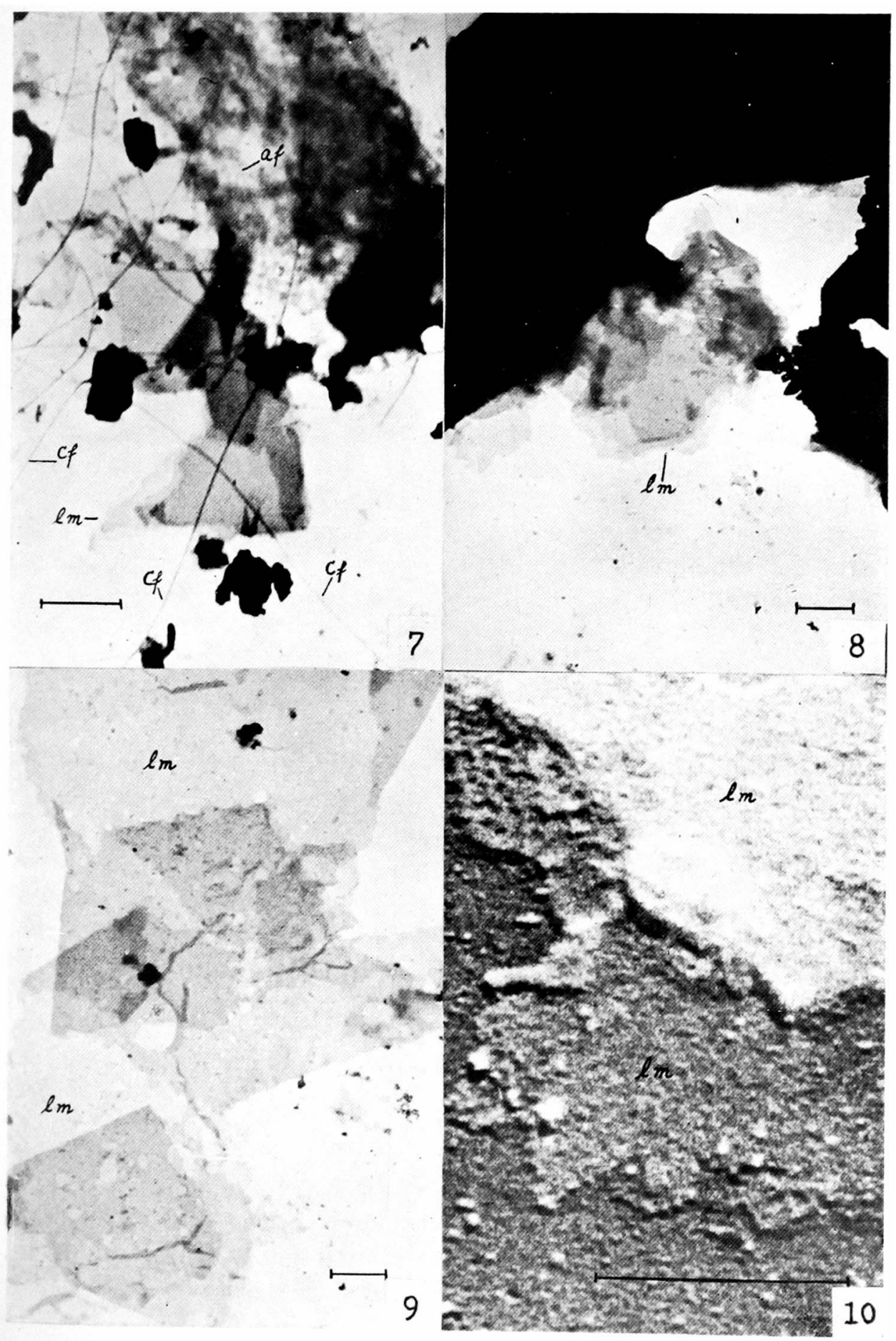

R. Honjin 